\title{
Teoría de la modernización y movilizaciones sociales contemporáneas. El caso de las protestas brasileñas de junio de 2013
}

Natal es la capital del estado brasileño Río Grande del Norte, ubicado en el extremo nororiental del país. El 13 de mayo de 2013, las autoridades de Natal -urbe con poco más de 800000 habitantes, según el Instituto Brasileño de Geografía y Estadística (Prefeitura

Diversos analistas internacionales sostuvieron que las protestas brasileñas de junio de 2013 fueron consecuencia del reciente crecimiento económico del país, el acelerado surgimiento de clases medias, el acrecentamiento de las expectativas sobre el gobierno, el incremento de la participación ciudadana y la debilidad de las instituciones políticas para gestionar esta situación. Dicha explicación se basaba, explícita o implícitamente, en la teoría de la modernización de Samuel P. Huntington (1968). El objetivo del presente trabajo es cuestionar si el modelo de causalidad de Huntington efectivamente explica las protestas brasileñas. Para lograrlo, se contrastan etnografías de las protestas con dicho modelo. A partir de ello, se discuten los alcances y límites de la teoría de la modernización para explicar las movilizaciones sociales contemporáneas.

Palabras clave: Brasil, modernización, movimientos sociales, protestas, Samuel P. Huntington.

- Estudiante de la Maestría en Ciencia Política de El Colegio de México gpetersen@colmex.mx
Municipal do Natal, 2013)- decidieron subir la tarifa del transporte público, como lo habían hecho a mediados del año anterior. Al inicio, hubo movilizaciones sociales dispersas y poco numerosas, igual que en 2012. Sin embargo, durante el mes de junio, la trayectoria de estas protestas dio un giro radical. Las de Natal pasarían a la historia como las primeras de una serie de multitudinarias movilizaciones en distintas ciudades brasileñas, que lograrían enorme notoriedad internacional, sobre todo por haberse llevado a cabo en el marco de la Copa FIFA Confederaciones 2013, celebrada en Brasil entre el 15 y el 30 de junio. Así, lo que arrancó como una serie de protestas aisladas en una ciudad media terminó en una puesta en jaque al gobierno 
nacional, con la presidenta Rousseff enfrentando el conflicto más agudo hasta ese punto de su gestión.

¿A qué respondían tan numerosas, súbitas e intensas manifestaciones? ¿Cómo Brasil, uno de los países promesa desde mediados de los noventa, y todavía más bajo la presidencia de Luiz Inácio "Lula" da Silva, se instalaba de pronto en el conflicto callejero y la inestabilidad política? ¿Por qué una medida tan específica y rutinaria como el ajuste a la alza del precio del transporte, simultáneo en distintas ciudades, conducía a decenas de miles de ciudadanos a protestar en el espacio público, enarbolando las más diversas demandas?

Las explicaciones que atendían las causas inmediatas de las protestas referían, por supuesto, al incremento en el precio del transporte. Sin embargo, otros análisis buscaban razones más de fondo, atendiendo a las causas más profundas de las movilizaciones. Como escribía, con ironía, Borón (2013): "Plantear que todo esto tiene que ver con el aumento de 20 centavos de real en el transporte público de San Paulo es lo mismo que, salvando las distancias, suponer que la Revolución Francesa se produjo porque algunas panaderías de la zona de la Bastilla habían aumentado en unos centavos el precio del pan".

Distintos analistas coincidieron en que algunas de las causas de las movilizaciones eran las exigencias crecientes hacia el Estado de clases medias surgidas tras el notable desempeño económico del país durante los últimos diez o quince años. Según esta hipótesis, dichos sectores habrían ascendido socioeconómicamente e incrementado sus expectativas, mientras el Estado -sus instituciones, políticas y servicios- no era capaz de cumplirlas. De hecho, hubo analistas de renombre que dieron a esta explicación -basada, explícita o implícitamente, en la teoría de la modernización de Huntington- un peso fundamental; otros, por su parte, la consideraban una entre varias. 
En un artículo para El País, Naím (2013), al analizar las protestas casi simultáneas en Turquía y Brasil, anotaba que "la principal sorpresa de estas protestas callejeras es que ocurren en países económicamente exitosos”. Según él, "Brasil no solo ha sacado a millones de personas de la pobreza, sino que incluso ha logrado la hazaña de disminuir su desigualdad [...] tienen hoy una clase media más numerosa que nunca". Apuntaba también que la clave para entender las movilizaciones se encuentra en Huntington (1972), donde se postula -en palabras de Naím (2013) - "que en las sociedades que experimentan transformaciones rápidas, la demanda de servicios públicos crece a mayor velocidad que la capacidad de los Gobiernos para satisfacerla. Esta es la brecha que saca a la gente a la calle a protestar contra el Gobierno".

En el mismo diario, y en fecha cercana, Arias (2013) apuntaba:

Los pobres llegados a la nueva clase media han tomado conciencia de haber dado un salto cualitativo en la esfera del consumo y ahora quieren más. Quieren, por ejemplo, unos servicios públicos de primer mundo, que no lo son; quieren una escuela que además de acogerles les enseñe con calidad, que no existe; quieren una universidad no politizada, ideologizada o burocrática. [...] Quieren hospitales con dignidad, sin meses de espera, sin colas inhumanas, donde sean tratados como personas. $Y$ quieren sobre todo lo que aún les falta políticamente: una democracia más madura.

La revista británica The Economist dedicó a Brasil su número del 28 de septiembre de 2013, titulado sugerentemente "Has Brazil blown it?” (“ßBrasil lo ha arruinado?”). La autora del artículo principal exponía:

Cuando la vida era una lucha por la supervivencia, la economía y el empleo eran las principales preocupaciones. Ahora que la gente está un

Teoría y DEBATE $\&$ No. 62 
poco mejor, el lamentable estado de la infraestructura y de los servicios públicos aparecen como sus prioridades. El gobierno ha intentado, pero en gran medida fracasado, responder a la creciente demanda de bienes públicos (Joyce, 2013).'

Además de estos análisis, que, al explicar las protestas, conferían un papel fundamental a la expansión de las clases medias, el crecimiento de las expectativas y la incapacidad del Estado para responder a las nuevas demandas, otros análisis tomaban en cuesta estos factores, aunque otorgándoles menor importancia, considerándolos como unas causas entre otras más. A decir de Castells (2013), por ejemplo, "en lugar de este despilfarro, que consideran manchado de corrupción [Copa Mundial de Fútbol, a celebrarse en 2014 en Brasil], quieren inversión pública en transporte, educación y salud”. Borón (2013) incluía, entre los muchos elementos que componían su explicación de las protestas, "temas tales como la pésima situación de los servicios de salud pública; el sesgo clasista del acceso a la educación”.

El presente ensayo busca poner a prueba la tesis de que la teoría de la modernización explica parcial o totalmente las protestas brasileñas, tal como estos planteamientos señalan. Para hacerlo, se recurre a etnografías de las protestas, en aras de conocer, a partir de datos primarios, sus características fundamentales y, sobre todo, dilucidar sus causas. Estas son después contrastadas con la explicación que da la teoría de la modernización a la inestabilidad política, para conocer hasta qué grado tal teoría explica las protestas en cuestión. Dicho más esquemáticamente, se recurre a datos primarios acerca de las protestas brasileñas

\footnotetext{
I. La traducción es propia: "When life was a struggle for survival, the economy and jobs were the main concerns. Now that people are a little better off, the parlous state of infrastructure and public services is at the front of their minds. The government has tried but largely failed to respond to growing demand for public goods".
} 
Teoría de la modernización y movilizaciones sociales contemporáneas

para conocer si las explicaciones de los analistas citados y de muchos otros no citados, que recurren a la teoría de la modernización, se sostienen empíricamente.

El trabajo está dividido en cuatro secciones. La primera sintetiza la explicación que da la teoría de la modernización de Huntington a la inestabilidad política en sociedades en cambio. Después, se recuperan datos clave de tres distintas etnografías de las protestas brasileñas (Kamnski y Chermont, 2013; Paes y Zanchetta, 2013; Saraiva, 2013), con especial atención a las causas de las movilizaciones. En la tercera sección se analiza en qué medida la teoría de la modernización de Huntington explica las protestas brasileñas, planteando algunas hipótesis alternativas desde Tarrow (1997), que resulta un adecuado contrapunto teórico a Huntington por priorizar en su teoría algunas causas de las movilizaciones que Huntington no trata. Por último, a manera de conclusión, se discuten los alcances y límites de la teoría de la modernización para explicar las movilizaciones sociales contemporáneas, con especial referencia al caso brasileño.

\section{Teoría de la modernización de Huntington}

Los planteamientos de Huntington en torno a la modernización se insertan en las discusiones inauguradas por Rostow (1961). Huntington aborda la inestabilidad política en contextos de modernización económica de países en desarrollo, sobre todo en Huntington (1972) y, en menor medida, en Crozier, Huntington y Watanuki (1975) ${ }^{2}$ y Huntington (1994).

La investigación de Huntington (1972) se enfoca en las consecuencias políticas de la modernización económica en

2. Se centra en Europa del Este, Japón y Estados Unidos, no en países en desarrollo, aunque presenta algunos planteamientos que también aplican a estos. 
países de Asia, África y América Latina. Para el autor, "la modernización es un proceso multifacético, que implica una serie de cambios en todas las zonas del pensamiento y la actividad humanas" (Huntington, 1972, p. 40). Huntington utiliza la definición de modernización de Lerner: "urbanización, industrialización, secularización, democratización, educación, participación en los medios de comunicación" (Lerner, 1958, p. 438) ${ }^{3}$. Además de los aspectos urbanos, económicos, culturales y comunicativos de la modernización, esta también tiene, para Huntington, una dimensión política: "La modernización implica, en gran medida, la multiplicación y diversificación de las fuerzas sociales" (Huntington, 1972, p. 20). Dicho en otros términos, la modernización supone "la creciente participación en política de grupos sociales de toda la comunidad" (Huntington, 1972, p. 42).

Según Huntington, la relación entre modernización e inestabilidad política no es directa, sino que implica otras tres variables: expectativas, participación y baja institucionalidad. La modernización hace crecer las expectativas, que, cuando no son cumplidas por los gobiernos, movilizan a la participación política. Esta participación deriva en inestabilidad cuando los gobiernos no pueden manejarla, por tener bajos niveles de institucionalización, es decir, cuando "el proceso por el cual adquieren valor y estabilidad las organizaciones y procedimientos" no se ha desarrollado plenamente (Huntington, 1972 p. 23). Para el autor, el modelo de causalidad que conecta modernización e inestabilidad es el siguiente:

La urbanización, el incremento de los índices de alfabetismo, educación

y acceso a los medios de comunicación sociales crean elevadas aspira-

3. La traducción es propia: "urbanization, industrialization, secularization, democratization, education, media participation". 
Teoría de la modernización y movilizaciones sociales contemporáneas

ciones y expectativas, que si no son satisfechas galvanizan a individuos y grupos y los empujan a la acción política. Ante la falta de instituciones políticas fuertes y adaptables, tales aumentos en la participación traen aparejada la inestabilidad y la violencia (Huntington, 1972, p. 53).

Por otra parte, la modernización también conduce a la inestabilidad política porque los cambios que implica, además de incidir sobre las expectativas y la participación política, "socavan los fundamentos tradicionales de la autoridad y las instituciones políticas tradicionales, y complican tremendamente los problemas de la creación de nuevas bases de asociación e instituciones políticas que unan la legitimidad a la eficacia" (Huntington, 1972, p. 16). Con este elemento sumado a los anteriores, el contexto es propicio para las movilizaciones sociales, pues "los ritmos de movilización social y el auge de la participación política son elevados; los de organización e institucionalización políticas, bajos. El resultado es la inestabilidad y el desorden" (Huntington, 1972 , p. 16). Dado que la modernización tiene entre sus procesos principales la urbanización, parte importante de la inestabilidad política ocurre en las ciudades: "la inestabilidad de la ciudad -que se expresa en golpes, desórdenes, manifestaciones- es en cierto modo una característica ineludible de la modernización" (Huntington, 1972, p. 78).

Huntington critica las teorías, bastante extendidas entonces, que relacionan pobreza e inestabilidad política. De hecho, en último término, su teoría de la modernización se encuentra en la antípoda de estos planteamientos. Para él, la pobreza no genera inestabilidad; lo que genera inestabilidad son los esfuerzos por erradicarla. Lo escribe así: "lo que produce desorden político no es la ausencia de modernidad, sino los esfuerzos por lograrla" (Huntington, 1972 , p. 48). Esta tesis, según el autor, también es válida al interior de los países, en la escala subnacional. "En los países que están en vías de modernización, la violencia,

Teoría y DEBATE No. 62 
el desorden y las manifestaciones extremistas son más frecuentes en las partes más ricas del territorio que en las más pobres" (Huntington, 1972, p. 51).

Ahora bien, la alternativa para evitar que la modernización apareje inestabilidad es fortalecer las instituciones. De hecho, para Huntington, es precisamente la diferencia en solidez institucional lo que explica que la modernización traiga inestabilidad en países de Asia, África y América Latina, y no en Europa del Este, Japón y Estados Unidos (Crozier, Huntington y Watanuki, 1975). "El principal problema de la política -apunta Huntington- es el atraso en el desarrollo de las instituciones políticas que deben respaldar los cambios económicos y sociales" (Huntington, 1972, p. 16).

Crozier, Huntington y Watanuki (1975) actualiza algunos de los planteamientos del libro publicado por Huntington tres años antes. Sin embargo, dado que los países bajo estudio en el libro de 1975 son altamente desarrollados en lo económico, no se aborda ahí, directamente, el funcionamiento de la democracia en países en desarrollo. Con todo, una de las tesis centrales del libro también ha sido aplicada a democracias de países en desarrollo. "En años recientes, las operaciones del proceso democrático parecen, en efecto, haber generado crisis de los medios tradicionales de control social, deslegitimación de las formas de autoridad, tanto políticas como de otro tipo, y sobrecarga de demandas sobre el gobierno, excediendo su capacidad para responder" (Crozier, Huntington y Watanuki, 1975, p. 8). ${ }^{4}$ Los tres procesos citados -crisis de los medios tradicionales de control, deslegitimación y sobrecarga de demandas a los gobiernos- aparecen también en Huntington (1972) y son característicos de la inestabilidad política en sociedades

4. La traducción es propia: "In recent years, the operations of the democratic process do indeed appear to have generated a breakdown of traditional means of social control, a delegitimation of political and other forms of authority, and an overload of demands on government, exceeding its capacity to respond". 
Teoría de la modernización y movilizaciones sociales contemporáneas

en cambio. Tal como Huntington señalaba en 1972, en los países con solidez institucional estos procesos no devienen en inestabilidad, lo que solo ocurre en países con bajos grados de institucionalización.

Según los autores, la expansión de las demandas hacia los gobiernos surge de:

(I) el involucramiento de una proporción creciente de la población en la actividad política, (2) el desarrollo de nuevos grupos y de nueva conciencia en antiguos grupos, incluyendo jóvenes, grupos regionales y minorías étnicas, (3) la diversificación de los medios y tácticas políticas que los grupos utilizan para asegurar sus fines, (4) una expectativa creciente de parte de los grupos de que el gobierno tiene la responsabilidad de cumplir con sus necesidades, y (5) una escalada de lo que ellos conciben que son esas necesidades (Crozier, Huntington y Watanuki, 1975, pp. 163-4). ${ }^{5}$

Estos cinco puntos son otra manera de plantear las consecuencias políticas de la modernización. Cuando se presentan en democracias altamente institucionalizadas, ciertamente generan problemas, pero no inestabilidad política; en cambio, en contextos de baja institucionalización política devienen en grados variables de inestabilidad.

Huntington (1994) estudia las transiciones a la democracia en más de treinta países entre 1974 y 1990, incluyendo varios casos de Asia y América Latina, cuya situación ya había sido abordada en Huntington (1972). En una panorámica del libro, el autor señala:

5. La traducción es propia: “(I) the involvement of an increasing proportion of the population in political activity; (2) the development of new groups and of new consciousness on the part of old groups, including youth, regional groups, and ethnic minorities; (3) the diversification of the political means and tactics which groups use to secure their ends; (4) an increasing expectation on the part of groups that government has the responsibility to meet their needs; and (5) an escalation in what they conceive those needs to be".

Teoría y DEBATE No. 62 
Durante los quince años siguientes al fin de la dictadura portuguesa en 1974, en aproximadamente treinta países de Europa, Asia y América Latina los regímenes autoritarios fueron reemplazados por otros democráticos. En otros países se produjo una considerable liberalización en los regímenes autoritarios. $Y$ aun en otros, los movimientos en pro de la democracia ganaron fuerza y legitimidad (Huntington, 1994, p. 33).

Huntington apunta que cinco procesos causaron directamente la tercera ola democrática: 1) los graves problemas de legitimación de los regímenes autoritarios; 2) el crecimiento económico mundial de los años sesenta; 3 ) los sorprendentes cambios en la doctrina y en las actividades de la Iglesia católica; 4) cambios en las políticas de los actores externos; y 5) el efecto "bola de nieve", debido al cual algunas sociedades intentaron imitar transiciones a la democracia logradas por otras que les servían de ejemplo (Huntington, 1994, pp. 53-4). Algunos de los casos estudiados, específicamente aquellos cuyo régimen autoritario entró en crisis después de periodos prolongados de crecimiento económico, pasaron por inestabilidades políticas que Huntington explica desde el modelo causal que relaciona crecimiento económico, creación de clases medias, expansión de expectativas sobre los gobiernos, incremento de la participación y una institucionalización política tan baja que los gobiernos enfrentan problemas para gestionar esta participación, lo que deriva, en último término, en inestabilidad política.

Huntington también alude a las causas del surgimiento de expresiones radicales en contextos de modernización económica y baja institucionalización política. Según sostiene, maneras extremistas de mostrar desacuerdo con el statu quo parten del fracaso continuo de las instituciones para responder a las demandas crecientes de la sociedad. "Las respuestas antioficialistas y antisistema son las clásicas reacciones democráticas al fracaso político y a la desilusión" (Huntington, 1994, p. 239). 
Teoría de la modernización y movilizaciones sociales contemporáneas

Las movilizaciones brasileñas de junio de 2013: un recuento etnográfico

A partir de las etnografías de Saraiva (2013), Paes y Zanchetta (2013) y Kamnski y Chermont (2013) se retoman datos primarios sobre las protestas brasileñas de mediados de 2013. Los datos recogidos se utilizan en la sección que sigue para definir en qué medida la teoría de la modernización explica estas movilizaciones. Cada una de las tres etnografías atiende a momentos diferentes de las protestas: Saraiva (2013) centra su atención en los orígenes y funcionamiento del Movimiento por el Pase Libre (MPL), el más importante para la detonación de las protestas. El autor estudia este movimiento desde 2010, cuando comenzó a investigarlo para su tesis doctoral. Paes y Zanchetta (2013) se enfocan, desde una óptica periodística, en los días más álgidos de las movilizaciones en São Paulo, del 6 al 20 de junio. Por último, Kamnski y Chermont (2013) etnografían un hecho en específico, ocurrido en la etapa final de las multitudinarias protestas: los enfrentamientos entre policías y manifestantes en las afueras del Estadio Aderaldo Plácido Castelo en la ciudad de Fortaleza, el 27 de junio de 2013.

Saraiva (2013) concede una enorme importancia a MPL en el surgimiento y expansión de las movilizaciones. Según él, las reivindicaciones de este grupo respecto al precio del transporte público fueron el principal detonante de las protestas:

El hecho de que un movimiento organizado como MPL actuara antes, durante y después de las 'erupciones de junio', precediendo, así, al 'elemento espontáneo' de las manifestaciones, fue lo que dio importancia al proceso por el transporte colectivo, al descenso de las tarifas incrementadas y al propio MPL como movimiento central y movilizador (Saraiva, 2013).

Teoría y DEBATE No. 62 
El autor aporta elementos importantes para caracterizar a MPL:

MPL es un movimiento social autónomo, integrado principalmente por jóvenes que luchan por la reestructuración del transporte público urbano y el derecho a la ciudad [...]. A partir de la lucha por el pase libre estudiantil y la mejora de las condiciones del transporte, el movimiento elaboró sofisticadas nociones de movilidad urbana, segregación espacial y segregación racial, que componen su visión de derecho a la ciudad (Saraiva, 2013).

MPL lucha por una "desmercantilización" del transporte público, al considerarlo un servicio que debería ser accesible para todos y no una mercancía, y enmarca esta reivindicación en una lucha contra el capitalismo. Según el autor, MPL se entiende mejor si se le observa como parte de "los grandes movimientos denominados 'antiglobalización' o 'alterglobalización', que se organizaron en varios lugares y asomaron masivamente a las calles de numerosas ciudades del mundo entre 1999 y 2002" (Saraiva, 2013). Otra de las características más distintivas de su ideología es un cierto libertarismo, que, según Saraiva, "abreva en el anarquismo del siglo XIX, el marxismo heterodoxo de principios del siglo XX, los movimientos contraculturales de 1960 y la 'autonomía' de los movimientos de 1970 y 1980 en Italia y Alemania” (Saraiva, 2013). Esta veta libertaria se manifiesta, por ejemplo, en "la propuesta de creación de consejos comunitarios para la gestión del transporte en cada ciudad [...], en una perspectiva de autogestión en el derecho a la ciudad" (Saraiva, 2013).

El movimiento se caracteriza a sí mismo como apartidista y sus principios más bien "revelan la influencia de concepciones autonomistas, anarquistas, zapatistas y altermundistas, mezcladas con una decepción que toca el 
Teoría de la modernización y movilizaciones sociales contemporáneas

funcionamiento de los partidos e instituciones políticas en general” (Saraiva, 2013) .

Los principios que guían el trabajo del movimiento se pueden agrupar en tres áreas: i) la primera se refiere, principalmente, a la relación trabada con actores/colectivos externos, con los cuales el movimiento se relaciona. Esos [principios] son: autonomía, apartidismo y federalismo; ii) la segunda expresa las relaciones establecidas entre los activistas dentro del movimiento: horizontalidad, no liderazgo y decisiones por consenso; iii) la tercera apunta a las características generales del movimiento, tales como: anticapitalismo [...] y no jerarquización de las luchas (Saraiva, 2013).

Uno de los aspectos más importantes de las protestas de junio es su dinamismo en el terreno discursivo. El asunto de la tarifa del transporte, el primero del que se ocuparon MPL y quienes se unieron inicialmente a sus demandas, pronto se convirtió en uno entre muchos. Con el paso de los días, el movimiento retomó una "serie de quejas que tiene la sociedad brasileña desde hace mucho tiempo y la sensación de no representación de parte de sus gobernantes y representantes" (Saraiva, 2013).

MPL también entra en la lista de movimientos que hacen un uso intensivo de las tecnologías de comunicación y, en cierto modo, se estructuran con una fluidez que la red inspira y permite. Facebook, correo electrónico, mensajes y comunicaciones por celular, etc., son fundamentales para su organización, contribuyendo, incluso, a la anhelada desconcentración del poder, agilizando en la distribución de información y tareas dentro del grupo (Saraiva, 2013) .

De esta manera, las tecnologías de información y comunicación no tienen solo un carácter instrumental para MPL-que de suyo es clave para el movimiento-, sino que posibilitan una distribución más equitativa del poder, lo que tiene 
también efectos políticos en su interior. Comunicarse por medio de la red no solo es más ágil y eficiente, sino más libre e igualitario.

Saraiva sostiene que no es difícil de explicar la simultánea irrupción de protestas callejeras muy parecidas entre sí en distintas ciudades brasileñas. "Esto ocurrió precisamente porque MPL es un movimiento urbano, que critica y se diferencia de las prácticas partidistas, que actúa por medio de acciones directas, y se guía por principios de horizontalidad y no liderazgo, conjunto de características que encuentran mucha resonancia en la sociedad contemporánea" (Saraiva, 2013) .

Paes y Zanchetta (2013) etnografiaron, desde el periodismo, las protestas en São Paulo en su momento más álgido, entre el 6 y el 20 de junio. Reportan específicamente observaciones de siete días, distribuidos en dos semanas: 6 , $7,11,13,17,18$ y 20 de junio. El jueves 6 "eran solo unos 150 chicos de MPL y estudiantes [...] enfrente del Ayuntamiento. Ya habían realizado manifestaciones similares otros años [...]. no obstaculizaron el tráfico y gritaron al unísono [en referencia al alza en la tarifa del transporte]: 'manos arriba, 3.20 es un robo"' (Paes y Zanchetta, 2013) . Así, las protestas eran en aquel momento poco numerosas y temáticamente focalizadas en el precio del transporte. "Pero la Policía Militar (PM) decidió actuar. Por exceso de celo -tal vez un error histórico- pasó a lanzar gases lacrimógenos" (Paes y Zanchetta, 2013). Esto, según los autores, se convertiría en un punto de inflexión en las movilizaciones, pues les atraería apoyos de distintos sectores, que engrosarían las filas de las protestas, y además radicalizaría a una parte de quienes protestaban: "comenzaría la osada táctica por parte de los manifestantes de reaccionar por medio de barricadas e interrupción del tráfico en horas pico. [...] Incluso sin tiempo para darse cuenta, [de] que algo nuevo e histórico estaba sucediendo" (Paes y Zanchetta, 2013). 
Teoría de la modernización y movilizaciones sociales contemporáneas

Al día siguiente, los enfrentamientos continuaron: los inconformes salieron de nueva cuenta a las calles y la policía trató de dispersarlos con gases lacrimógenos. "Una neblina tóxica no asustó a los jóvenes, que comenzaron a correr de la $\mathrm{PM}$, a concentrarse en nuevos puntos y a interrumpir otras calles con barricadas" (Paes y Zanchetta, 2013). Los choques continuarían la siguiente semana, en particular el martes 11. Para esta fecha, el número de participantes en las protestas totalizaba varios miles, con una porción importante que se había involucrado después de enterarse mediante Internet, sobre todo en las redes sociales. "Las redes sociales comenzaron a mostrar su potencial. En la tercera protesta, los jóvenes y adolescentes que no tenían en su timeline de Facebook una foto de la marcha estaban cometiendo un suicidio social. Serían unos fracasados en la escuela. Doce mil personas asistieron" (Paes y Zanchetta, 2013).

A decir de los autores, "El cuarto día de protestas [jueves 13] debe ser nombrado el capítulo decisivo de la novela. La población parecía ya cansada de estar atrapada y había en el aire un clima de apoyo a que la PM emprendiera acciones más enérgicas. La policía estaba en la calle dispuesta a mantener la Avenida Paulista libre. Cerca de 5,000 personas asistieron" (Paes y Zanchetta, 2013) . La policía utilizó balas de goma contra los manifestantes, lo que escaló notablemente la violencia en los enfrentamientos. En contra de lo que esperaban las autoridades, esto implicó un giro fundamental, pues hizo crecer más las movilizaciones y orientó la opinión pública en su favor, lo que comenzó a hacer presión sobre las autoridades. Tan solo cuatro días después, el lunes 17 sucedió que:

Cerca de 100 mil personas salieron a las calles [...] Facebook se había tornado prácticamente monotemático. Fue evidente para los jóvenes la incapacidad de la PM para hacer frente a la novedad política que surgía. El Secretario de Seguridad Pública, Fernando Grella, sintió el peso de 
la opinión pública y dictaminó que la policía actuara de choque solo si era absolutamente necesario (Paes y Zanchetta, 20I3 ).

A pesar de la dimensión e intensidad que habían logrado las protestas, aún el martes 18 "los políticos se mantenían irreductibles [...] y no reducían la tarifa. Fue entonces cuando los anarquistas del Black blocks decidieron entrar en acción” (Paes y Zanchetta, 2013) . Esto marcaría un nuevo punto de quiebre, pues el endurecimiento de las tácticas de agresión de los grupos más radicales de los movilizados lograría resultados. "Cuando todos esperaban otra marcha pacífica, con 30 mil personas, São Paulo vivió tres horas de caos en manos de 300 jóvenes. El edificio del Ayuntamiento, el Teatro Municipal y el monumento de la Plaza del Patriarca fueron desfigurados; 20 tiendas destruidas y saqueadas. La PM no actuó" (Paes y Zanchetta, 2013) . La novedad era doble: por un lado, la presión violenta de una parte de los manifestantes; por el otro, la no respuesta de parte de la policía ante abiertas violaciones a la ley. Dos días después, el jueves 20, "la estrategia de la violencia dio resultados. El alcalde y el gobernador rescindieron los aumentos. En la séptima marcha, 100,000 personas fueron a la Avenida Paulista, con diversas demandas. Las calles habían demostrado su fuerza" (Paes y Zanchetta, 2013) .

Kamnski y Chermont (2013) describen los enfrentamientos entre policías y manifestantes en las afueras del Estadio Aderaldo Plácido Castelo de Fortaleza el 27 de junio, en el declive de las movilizaciones. Una dimensión en que los autores hacen especial hincapié es la diversidad de las reivindicaciones. "Hay muchas voces para expresar la crisis de representatividad, de la democracia representativa, la crisis que se expresa en la precariedad del mundo del trabajo y de las condiciones de vida en el capitalismo tardío, en el frágil y débil sistema político que ha quedado frente a la cibercultura" (Kamnski y Chermont, 2013) . 
Teoría de la modernización y movilizaciones sociales contemporáneas

Sin embargo, eso no era todo, sino que también se aludía a "la lucha secular por la reforma agraria, la educación, la dignidad en la atención a la salud, contra la corrupción, los excesos y la distancia de la clase política, contra la falacia del régimen democrático de baja intensidad" (Kamnski y Chermont, 2013) .

Otro aspecto de las protestas que destaca esta etnografía es la severidad de los choques entre policías y manifestantes. Se trata de una descripción detallada de un ambiente atravesado por emociones de miedo y muestras de violencia.

En medio de la multitud aterrorizada, atrapada entre quioscos, árboles, automóviles, paredes y casas, el humo se propaga rápidamente, ipenetrando en los ojos, la piel y los pulmones! La ceguera temporal, en una fracción de segundo, efecto vertiginoso de la lucha por los derechos, el derecho a decidir nuestro propio destino como nación (Kamnski y Chermont, 2013).

Movilizaciones brasileñas: ¿en qué medida las explica la teoría de la modernización?

A continuación se analiza qué tanto la teoría de la modernización de Huntington explica las protestas brasileñas, planteando explicaciones alternativas a partir de Tarrow (1997), quien analiza las movilizaciones sociales en una lógica distinta a la de Huntington, complementaria en algunos puntos pero sobre todo contrapuesta.

A lo largo de los últimos diez años, Brasil logró mantener un importante desempeño económico, que ha venido decayendo ligeramente en meses recientes. Entre 2004 y 2008, la economía brasileña experimentó un crecimiento del PIB de entre 3 y $6 \%$ anual en términos reales. La crisis de 2008 provocó que el crecimiento económico de 2009 fuera negativo, aunque solo mínimamente, apenas unas décimas, a diferencia de otros países de la región que cayeron fuer-

Teoría y DEBATE $\&$ No. 62 
temente. Tras la contracción, la economía brasileña creció más de $7 \%$ en 2010, ritmo que disminuiría los dos años siguientes pero seguiría siendo positivo, debajo de 3\% (De Conti, 2013, p. 4).

Según De Conti, los logros más importantes de la economía brasileña en los últimos diez años han sido:

la reducción de la pobreza y el mejoramiento de la distribución del ingreso, la reducción de la tasa de desempleo y la disminución de la vulnerabilidad externa. Además de eso, otra característica importante es que estos logros se obtuvieron manteniendo las tasas de inflación en un nivel razonablemente bajo (...), y una reducción considerable de la deuda neta del sector público, que era del $39 \%$ del PIB en 2002 y está en 32\% en 2012 (De Conti, 20I3, p. 3I). ${ }^{6}$

Con base en este notable desempeño económico, Brasil pasó por un intenso proceso de modernización. "En 1950, la población urbana de Brasil fue de $36,2 \%$. Según el último censo, en $2010,84,45 \%$ de los brasileños vivía en ciudades" (Willaarts, Pardo y De la Mora, 2013, p. 5) ${ }^{7}$ y ahí se produce alrededor del 90\% del PIB (Willaarts, Pardo y De la Mora, 2013, p. 6). La modernización en Brasil también se ha expresado en mayor dinamismo del mercado laboral y en menor desigualdad en el ingreso.

Su coeficiente de Gini pasó de 0.596 en $200 \mathrm{I}$ a 0.543 (en 20I I) y la reducción de la pobreza mostró un desempeño espectacular, cayendo de $37.5 \%$ a $20.9 \%$ en un período de diez años (200I a 20 I I) [...]. Los

\footnotetext{
6. La traducción es propia: "the reduction of poverty and the amelioration of income distribution; the reduction in unemployment rate; and the decrease in external vulnerability. Moreover, another important feature is that these achievements were obtained with the maintenance of the inflation rates at a reasonably low level $[\ldots]$ as well as considerable reduction of the net public sector debt, from a level of $39 \%$ of the GDP in 2002 to a level of $32 \%$ in 2012 ".

7. La traducción es propia: "In 1950 Brazil's urban population was $36.2 \%$. According to the last census, in $201084.45 \%$ of Brazilians lived in cities".
} 
Teoría de la modernización y movilizaciones sociales contemporáneas

hogares de clase media han aumentado más del doble: de 9.3 millones en 1990 a 20.8 millones en 2007, lo que representa un aumento de $36 \%$ a $46 \%$ del total de hogares. Además, Brasil es, junto con México, uno de los dos países que más aumentaron la participación de la mujer en el mercado laboral en las últimas dos décadas (Willaarts, Pardo y De la Mora, 2013, p. 6). ${ }^{8}$

La teoría de la modernización de Huntington sostiene que procesos acelerados de modernización generan nuevas clases medias, expanden sus expectativas y puede provocar, a la larga, inestabilidad política. Las protestas brasileñas efectivamente ocurrieron tras un acelerado proceso de modernización económica. El crecimiento brasileño no solo hizo ascender socioeconómicamente a una parte importante de quienes se movilizaron masivamente, sino que también les hizo incrementar sus expectativas sobre los servicios que debía brindarles el Estado, que, al verse frustradas, condujeron a la participación política fuera de los canales institucionales. Este es uno de los aspectos en la teoría de la modernización de Huntington que efectivamente explica las movilizaciones brasileñas. La primera reivindicación de las protestas estaba asociada con el precio del transporte público, a manera de una exigencia hacia las autoridades para que garanticen este servicio público sin elevar la tarifa.

Para Huntington la inestabilidad política no se relaciona con la pobreza, sino con los intentos por erradicarla. En este sentido, las protestas brasileñas surgieron después de que en Brasil se lograra un eficaz combate a la pobreza.

8. La traducción es propia: "Its Gini coefficient dropped from 0.596 in 200 I to 0.543 and the reduction of poverty showed the most spectacular, falling from $37.5 \%$ to 20.9 in a ten-year period ( 2001 to 2011 ) [...] Middle class households have more than doubled: from 9.3 millions in 1990 to 20.8 millions in 2007, which represents an increase from $36 \%$ to $46 \%$ of total households. In addition, Brazil is along with Mexico one of the two countries that most increased their participation of women in the labor market over the last two decades".

Teoría y DEBATE No. 62 
A partir de 2003, [...] más de 22 millones de personas han superado la línea de la pobreza hasta 2009 , lo que representa aproximadamente 14.3\% de la población brasileña. Además, 12.5 millones de personas han superado la línea de pobreza extrema, lo que significa una reducción del $50 \%$ en la pobreza extrema en sólo seis años (De Conti, 2013, p. 27). ${ }^{9}$

Junto con este proceso de modernización, hubo una multiplicación y diversificación de fuerzas sociales que buscaron participar políticamente, tal como lo predice Huntington (1972). Esto se ve reflejado en que las protestas pasaron, en tan solo once días, de apenas unos cientos de manifestantes a cerca de 100 000. Tarrow (1997, p. 17) sostiene que "los movimientos sociales [...] surgen cuando se dan las oportunidades políticas para la intervención de agentes sociales que normalmente carecen de ellas". El incremento en la tarifa del transporte movilizó a fuerzas sociales que quizá no lo habrían hecho sin este detonante, pero que difícilmente se habrían activado con tanta rapidez sin un alto nivel de politización previo.

El planteamiento huntingtoniano en torno a la modernización concibe las respuestas antisistema como parte de las reacciones ante el fracaso político. La participación de grupos anarquistas en las movilizaciones paulistanas se enmarcaría en esta lectura, toda vez que, hacia el final de las protestas, recurrieron a tácticas de violencia como medio para conseguir sus objetivos. Sin embargo, la teoría de Huntington no sirve para explicar a fondo el papel de estos grupos y sus tácticas en las protestas, porque su involucramiento no solo fue una expresión extrema de descontento ante la desilusión política, sino que se convirtió en un punto de inflexión. De hecho, a partir de esta presión el gobierno decidió revertir el alza en

9. La traducción es propia: "From 2003 onwards, [...] more than 22 million persons surpassed the poverty line by 2009 , representing approximately $14.3 \%$ of the Brazilian population. Moreover, 12.5 million persons have surpassed the extreme poverty line, reflecting a $50 \%$ reduction in extreme poverty in only six years". 
Teoría de la modernización y movilizaciones sociales contemporáneas

la tarifa. Así, Huntington acierta al incluir las reacciones antisistema en su planteamiento en torno a la inestabilidad política, pero lo hace de manera apenas marginal y falla en tanto que no describe la importancia táctica de estas manifestaciones en el conjunto de las movilizaciones.

En el caso de las protestas brasileñas, no hay elementos para sostener que la inestabilidad haya alcanzado tal grado por la debilidad de las instituciones. Más bien parece que el engrosamiento de las protestas, la ampliación de sus reivindicaciones y el crecimiento de sus apoyos externos, ocurrieron en gran medida a causa de la represión institucional, misma que visibiliza la fuerza del Estado, no su debilidad. Es decir, lo que multiplicó las protestas no fue la debilidad de las instituciones y sus consecuentes problemas para gestionar las demandas sociales, sino más bien la decisión gubernamental de utilizar la fuerza pública. Ultimadamente, las instituciones brasileñas se mostraron fuertes, cuando menos en términos coercitivos. Además, habían logrado elevar las tarifas del transporte en años previos, sin que se presentara mayor oposición, lo que también denota capacidad institucional, que difícilmente se perdió de un año a otro. Un error estratégico de las autoridades fue elevar la tarifa del transporte al mismo tiempo en distintas ciudades, lo que permitió que las diferentes oposiciones se coordinaran o, cuando menos, trataran de emularse unas a otras. En este sentido, la diferencia en el papel de las autoridades en 2013 y años precedentes no radicó en su fortaleza o debilidad institucional, sino en cómo utilizaron su capacidad en 2013.

Tarrow sostiene que "Es el reconocimiento de una comunidad de intereses lo que traduce el movimiento potencial en una acción colectiva [...] los líderes sólo pueden crear un movimiento social cuando explotan sentimientos más enraizados y profundos de solidaridad e identidad" (1997, p. 24). La movilización social se explica también por ele-

Teoría y DEBATE $@$ No. 62 
mentos simbólicos, tales como reconocimiento, solidaridad e identidad. La teoría de la modernización de Huntington explica la movilización a partir de condiciones materiales, derivadas de procesos intensos de modernización y, más en particular, como reacción a estos procesos. Desde Tarrow, la explicación de las protestas no puede ser solo material, sino que se ha de considerar la dimensión simbólica y entender ambas en función de las intenciones de los actores sociales, no solo como reacción a circunstancias externas.

Según Tarrow, en la base de los movimientos "se encuentran las redes sociales y los símbolos culturales a través de los cuales se estructuran las relaciones sociales. Cuanto más densas sean las primeras y más familiares los segundos, tanto más probable será que los movimientos se generalicen y perduren" (Tarrow, 1997, p. 17-8). Hay una dimensión simbólica en las protestas brasileñas, y sobre todo en MPL, que reivindica el derecho a la ciudad, con ciertas vetas libertarias y hasta anarquistas, en el marco de una crítica a la fase actual del capitalismo; no solo se trata, como señala la tesis de Huntington, de mayores demandas al Estado, participación y expectativas en expansión, y debilidad de las instituciones.

Cuando las protestas tomaron un carácter masivo, se multiplicaron las demandas, llegando inclusive a asuntos como reforma agraria, educación y la representación en la democracia imperante. Las protestas son, pues, diversas, dinámicas y con una lógica interna en la producción de discursos. Tratar de encasillarlas como mera reacción a un conjunto de cambios urbanos, económicos, culturales y comunicativos, englobados bajo el concepto de modernización -como lo sugiere Huntington-, es simplificar tanto la complejidad de sus reivindicaciones como la de sus resortes simbólicos -reconocimiento, solidaridad e identidad.

De hecho, parte de las reivindicaciones, sobre todo de MPL, son postmaterialistas y poco tienen que ver con la explicación materialista en que se centra Huntington. 
Teoría de la modernización y movilizaciones sociales contemporáneas

Inglehart (1998, p. 3) detecta en las sociedades industriales "un cambio gradual desde los valores 'materialistas' (sobre todo la seguridad física y económica) hacia las prioridades 'postmaterialistas' (sobre todo la autoexpresión y la calidad de vida)". Que MPL se haya interesado en el derecho a la ciudad, en especial en lo relativo a la movilidad urbana, segregación espacial y segregación racial evidencia su interés en cuestiones más allá de lo material y, con ello, también más allá de la modernización.

La diversidad de MPL y, en general, de quienes se integraron a las protestas, incluía una veta anarquista, que -como sostiene Saraiva (2013) - se conecta con concepciones autonomistas, anarquistas, zapatistas y altermundistas. Una parte de quienes protestaron apostaba por la autonomía frente al Estado y por la gestión de problemas desde la sociedad. La diversidad de las protestas permite que incorporen también estos discursos, que si bien no embonan con la demanda originaria -relativa, de hecho, a un servicio brindado por el Estado-, se convierten en parte de las reivindicaciones principales. También se plantearon fuertes críticas al neoliberalismo, al capitalismo y a la globalización, que tampoco entran en la lógica de expectativas crecientes hacia el Estado, a las que concede tanta importancia la teoría de la modernización. De hecho, con estos ataques al modelo de desarrollo imperante, las movilizaciones se interesaron también en la economía a escala mundial, no solo en inconformarse con la falta de respuesta de las instituciones.

Las nuevas tecnologías de información y comunicación fueron fundamentales para la coordinación de las protestas, pues, además de ser gratuitas, permiten llegar a grandes porciones de la población, lo que reduce costos de organización. Como dice Tarrow, "agrupar a la gente en una acción colectiva coordinada en momentos estratégicos de la historia requiere una solución social, lo que llamaré la necesidad de solventar los costes sociales transaccionales 
de la acción colectiva" (Tarrow, 1997, p. 20-1). Huntington comete el error de no considerar suficientemente a los medios de comunicación de los años setenta -la década en que desarrolló el grueso de su teoría de la modernización-al explicar la inestabilidad política. Solo coloca a los medios como parte del proceso de modernización, pero no como un elemento constitutivo de los movimientos que propician la inestabilidad política. En un entorno comunicativo extremadamente distinto al de aquellos años, el caso de Brasil demuestra que los medios son, en efecto, factor clave en la organización de los movimientos. Sería absurdo esperar que la teoría de la modernización considerara la tecnología actual al explicar la inestabilidad política de los sesenta y setenta. Su deficiencia es que no considera a fondo las comunicaciones de su entonces para explicar las protestas, cuando es difícil soslayar su importancia en la coordinación de miles de personas en torno a objetivos comunes.

Las posibilidades que abren las nuevas tecnologías de información y comunicación para colaborar en red permiten a los movimientos, por una parte, mayor eficiencia para organizarse, y, por la otra, carecer de líderes identificables y dispersar el poder en estructuras horizontales, en oposición a burocráticas y jerarquizadas. Esto es de enorme importancia para las movilizaciones, pues los medios de comunicación -y en particular las redes sociales- no son solo importantes logísticamente, sino también políticamente. En último término, influyen en la configuración de nuevas identidades y promueven una cultura política basada en la dispersión del poder, la falta de centros directivos y la crítica de las jerarquías, en un enfoque de democracia radical.

Según Castells, esta es una de las principales características de lo que llama "movimientos sociales en la era del Internet": "la horizontalidad de las redes favorece la colaboración y la solidaridad, socavando la necesidad de un liderazgo formal" (Castells, 2012b, p. 215). Para el autor: 
Teoría de la modernización y movilizaciones sociales contemporáneas

Esta estructura descentralizada maximiza las oportunidades de participación en el movimiento, teniendo en cuenta que estas redes son abiertas, sin límites definidos, y se reconfiguran continuamente de acuerdo con el nivel de participación de la población. También reduce la vulnerabilidad del movimiento a las amenazas de represión, ya que hay pocos objetivos específicos que reprimir, excepto los lugares ocupados, y la red puede reformarse siempre que haya suficientes participantes en el movimiento [...]. La conexión en red como forma de vida del movimiento le protege tanto de sus adversarios como de los propios peligros internos de burocratización y manipulación (Castells, 20I2b, p. 2I2).

Modernización y movilizaciones sociales contemporáneas: alcances y límites

A continuación se discuten, a manera de conclusión, los alcances y límites de la teoría de la modernización para explicar las movilizaciones de junio de 2013 en Brasil, desde una perspectiva más abstracta que la sección precedente. Esta misma discusión, o cuando menos algunas de sus partes, también puede aplicarse a la capacidad explicativa de la teoría de la modernización de Huntington ante otras protestas contemporáneas.

De entrada, el planteamiento de Huntington es útil para describir uno los múltiples contextos propicios para el surgimiento de inestabilidades políticas: la modernización económica, la cual no es una condición necesaria para que estas ocurran -ni mucho menos es condición suficiente-, pero es cierto que las expresiones masivas de descontento tienden a aparecer cuando esta es un elemento del contexto. La modernización no es la única explicación a las movilizaciones, pero sí una explicación que, de hecho, explica parcialmente el caso brasileño, sobre todo en sus inicios. Antes de las protestas, Brasil había pasado por un intenso proceso de modernización económica, el cual hizo crecer las expectativas y multiplicó las fuerzas sociales con participación 
política. La modernización de Brasil se refleja en indicadores como crecimiento del PIB, la reducción de la desigualdad, una mayor participación de la mujer en el mercado laboral y un proceso de urbanización. Las protestas iniciales en torno al incremento de la tarifa del transporte son producto de un contexto de expectativas crecientes, y la rapidez con que se sumaron decenas de miles de brasileños a las protestas denota una alta propensión al involucramiento político.

Con todo, una debilidad de la explicación huntingtoniana, que pone especialmente de relieve el caso brasileño, es que esta asocia las causas de la movilización social exclusivamente con el contexto, no con factores endógenos a la propia movilización. Y así como no puede desconocerse la importancia del contexto al explicar cualquier protesta, tampoco pueden soslayarse las intenciones y acciones específicas de quienes deciden movilizarse. Por más que haya condiciones estructurales para una protesta, solo habrá protesta si quienes están inconformes deciden salir a las calles y cuentan con la capacidad organizativa para iniciar las movilizaciones y sostenerlas en el tiempo. Pasar por alto la lógica interna de los movilizados al explicar las protestas es un error particularmente grave en el caso bajo estudio, pues dentro de MPL hubo una intensa actividad política desde hace años, como demuestra Saraiva (2013).

La explicación de Huntington es de corte materialista, sobre todo al dar cuenta de las causas de las movilizaciones. Según el autor, las demandas de quienes se movilizan en contextos de modernización están dirigidas al Estado, que se muestra incapaz de satisfacerlas. Con esta perspectiva, pasa por alto la dimensión simbólica de los movimientos. En el caso brasileño, el detonante es, efectivamente, materialista -la tarifa-, pero varias de las reivindicaciones posteriores exceden el ámbito de lo material -derecho a la ciudad, segregación espacial, segregación racial, representatividad política. Además, dentro de MPL hay una veta anarquista, 
Teoría de la modernización y movilizaciones sociales contemporáneas

cuyas reivindicaciones principales no son materiales y, por su propia naturaleza, ni siquiera están referidas al Estado. La teoría de la modernización no toma en cuenta ni la dimensión simbólica de los movimientos ni las expresiones dentro de estos que, aun en un entorno de modernización y expectativas crecientes, no recurren al Estado para la solución de sus problemas.

La debilidad de las instituciones en contextos de creciente participación política no necesariamente deriva en inestabilidad política ni la existencia de instituciones fuertes necesariamente la evita. De hecho, el uso de la coacción, que en principio refleja instituciones fuertes, cuando menos para reprimir, puede provocar el desbordamiento de las movilizaciones sociales, como ocurrió en el caso revisado. Así, no es solo la solidez o debilidad institucional lo que explica que se generen o no contextos de inestabilidad política -como sostiene Huntington-, sino también las decisiones que toman quienes encabezan estas instituciones, la coyuntura en que las toman -caracterizada, en el caso estudiado, por el aumento simultáneo de la tarifa en distintas ciudades-y la reacción de quienes enfrentan las consecuencias.

El único papel que le otorga Huntington a la comunicación al explicar la inestabilidad política es que forma parte de los procesos propios de la modernización, que -para él- es la causa última de la inestabilidad en sociedades en cambio. El autor omite la consideración de los medios de comunicación y de la interacción comunicativa como elemento constitutivo del proceso mediante el que se gestan las movilizaciones y perduran. Esta carencia de su teoría es particularmente notoria, vista desde ahora, dada la importancia que ha adquirido la comunicación. Actualmente no puede entenderse una movilización social sin atender a sus procesos de comunicación, sobre todo aquellos dentro de lo que Castells llama "autocomunicación de masas", es decir, aquella que se realiza por redes y cuyo "contenido

Teoría y DEBATE No. 62 
está autogenerado, su emisión autodirigida y su recepción autoseleccionada por todos aquellos que se comunican" (Castells, 2012a, p. 108). Sin embargo, aun cuando ya desde los sesenta y setenta las protestas guardaran complejas relaciones con los medios de comunicación, sobre todo con la radio y la televisión, los principales entonces, estos no son tomados en consideración por Huntington.

En el caso brasileño, el planteamiento de Huntington es pertinente para describir las condiciones estructurales propicias para el surgimiento de las movilizaciones. La mezcla de modernización, expectativas crecientes y mayor participación política explica el apoyo que logró la demanda de que no se incrementara la tarifa del transporte. Pero fuera de este aspecto, sería erróneo usar la teoría de la modernización -o cuando menos parcial- para explicar lo ocurrido. Algunos de sus errores e insuficiencias datan desde que se escribió, y estos no tienen que ver con las profundas diferencias entre aquel tiempo y el actual, si bien es cierto que otros tantos se deben a las profundas transformaciones que ha habido de entonces a la fecha, en términos de desarrollo económico, participación política e interacción comunicativa. En consecuencia, sería un equívoco subsumir el caso brasileño en un planteamiento que, como cualquiera, tiene errores e insuficiencias que hacen difícil que explique en su totalidad casos concretos, pero que, sobre todo, fue pensando en y para un entorno radicalmente diferente del actual. De modo que convendría más imaginar nuevas maneras de explicar las movilizaciones sociales de nuestro tiempo, ante las dificultades que muestran para ello algunas de las antiguas teorías.

Fecha de recepción: 11 de marzo de 2014

Fecha de aprobación: 09 de septiembre de 2014 
Teoría de la modernización y movilizaciones sociales contemporáneas

Arias, J. (2013). ¿Por qué Brasil y ahora? Disponible en Accesado el 30 de septiembre de 2013, en http:// internacional.elpais.com/internacional/20 I3/06/l7/ actualidad/I37|4324|3_|99966.html

Borón, A. (20I3). Un nuevo comienzo. Disponible en http://www. pagina I 2.com.ar/diario/elmundo/4-222898-20I3-06-23. html

Castells, M. (2012a). Comunicación y poder. México: Siglo XXI. (20I2b). Redes de indignación y esperanza. Los movimientos sociales en la era del Internet. Madrid: Alianza. - (20I3). Brasil: escuchar la calle. Disponible en http://www.lavanguardia.com/opinion/articulos/20I30629/54377068734/brasil-escuchar-a-la-calle. html

Crozier, M., S. Huntington, y J. Watanuki (1975). The crisis of democracy. Nueva York: New York University Press.

De Conti, B. (20I3). The main trends in the brazilian economy over the last ten years. Disponible en http://finance-andtrade.htw-berlin.de/fileadmin/working_paper_series/ wp_06_2013_De_Conti_The_Main_Trend_in_the_Brazilian_Economy.pdf

Huntington, S. (1972). El orden político en las sociedades en cambio. Barcelona: Paidós.

(1994). La tercera ola. La democratización a finales del siglo XX. Buenos Aires: Paidós.

Inglehart, R. (1998). Modernización y posmodernización. Cambio cultural, económico y político en 43 sociedades. Madrid: Centro de Investigaciones Sociológicas/Siglo XXI.

Joyce, H. (2013). Grounded. Disponible en http://www. economist.com/news/special-report/2 I 586667 having-come-tantalisingly-close-taking-brazil-has-stalledhelen-joyce-explains

Kamnski, R., y Chermont, L. (20I3). As crianças e a multidão na Arena Castelão: um relato etnográfico de um protesto

Teoría y DEBATE No. 62 
Bibliografía

no Brasil contemporâneo. Disponible en http://www. academia.edu/3804787/AS_CRIANCAS_E_A_MULTIDAO_NA_ARENA_CASTELAO_UM_RELATO_ ETNOGRAFICO_DE_UM_PROTESTO_NO_BRASIL_ CONTEMPORANEO

Lerner, D. (1964). The passing of traditional society. Nueva York: The Free Press of Glencoe / Collier Macmillan Limited

Naím, M. (20I3). Turquía, Brasil y sus protestas: seis sorpresas. Disponible en http://internacional.elpais.com/internacional/20 I3/06/22/actualidad/I37| 90 I 704_006203.html Paes, B., y Zanchetta, D. (20I3). A revolta do gás lacrimogêneo (em sete capítulos). Disponible en http://www.estadao. com.br/noticias/nacional,a-revolta-do-gas-lacrimogeneo-\%28em-sete-capitulos\%29, I 0457 I6,0.htm

Prefeitura Municipal do Natal (2013). História. Disponible en http://portal.natal.rn.gov.br/natal/ctd-669.html

Rostow, W. (196I). Las etapas del crecimiento económico. Un manifiesto no comunista. México: Fondo de Cultura Económica.

Saraiva, A. (20I3). O MPL e as 'manifestações de junho' no Brasil. Disponible en http://uninomade.net/tenda/o-mple-as-manifestacoes-de-junho-no-brasil/

Tarrow, S. (1997). El poder en movimiento. Los movimientos sociales, la acción colectiva y la política. Madrid: Alianza.

Willaarts, B., I. Pardo, y G. De la Mora (20I3). Urbanization, socio-economic changes and population growth in Brazil: dietary shifts and environmental implications. Disponible en http://www.iussp.org/sites/default/files/event_call_ for_papers/IUSSP\%20Willaarts,\%20Pardo\%20y\%20 de\%20la\%20Mora.pdf 